\title{
Deterioration of Structures in Sea Water
}

$\mathrm{N}^{\mathrm{o}}$

OT the least important of the matters which concern the civil engineer engaged on port and maritime works, such as docks, jetties, wharves and piers, is the durability in a marine environment of the materials available for con. structional purposes. Timber, iron and steel and concrete immersed in sea water are exposed to the action of agencies producing damage and

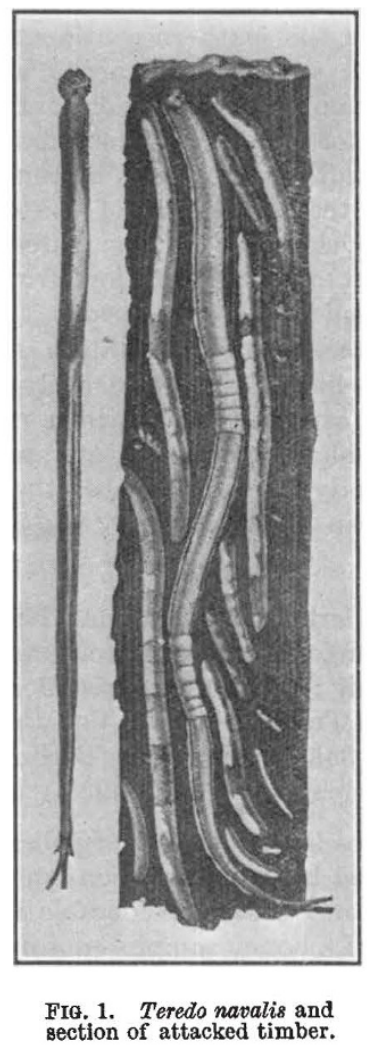

deterioration to a far higher degree than those characteristic of a purely atmospheric environment. Timber is not only particularly prone to 'rot' or decay at or about the water-line, especially if that fluctuates in level, but also it is assailed by marine organisms of highly destructive capability, while the chemical action of the salts in sea water is equally potent, under suitable conditions, in causing and fostering corrosion in metals and disintegration in concrete. When, therefore, the Institution of Civil Engineers, in 1920, instituted a Committee of Inquiry into the Deterioration of Structures in Sea Water, it took a step which had long been desirable and which, it may confidently be asserted, has been of inestimable advantage both to the profession and to the public at large. An investigation of the kind in question is bound to be prolonged, since certain deleterious processes are slow in action, though their cumulative effect over a number of years may be extremely serious and even fatal. Each year, the Committee has published the results of its inquiries in the form of interim reports, and now it is felt that the time has come when it is fitting to issue a connected account of the whole of the investigations which have been carried out up to date, and the conclusions which, in the opinion of the Committee, may reasonably be drawn from the results so far obtained.

This has been done in a volume which has been published by the Department of Scientific and Industrial Research* embodying the fifteenth report of the Institution Committee, though the Department is careful to state that it is not responsible for the statements made or the opinions expressed therein. A similar disclaimer is made by the Institution as regards endorsing the views of contributors whose names appear in connexion with their work.

The Report comprises four sections, relating respectively to the preservation of timber, the corrosion of steel and iron, the protection of steel and iron by means of paints and other preservatives, and lastly, the deterioration of reinforced concrete.

Omitting decay, the principal cause of damage to timber structures in sea water is the Teredo or Bankia, commonly known as the ship-worm, and certain allied species (Fig. 1). The ravages of these molluscs were evident in the earliest days of shipbuilding, and they are recorded to have proved disastrous in the fourth voyage of Columbus, whose ships were "pierced with worm-holes like a bee-hive". At the present day, the damage done to timber piling in various parts of the world may be reckoned in millions of pounds. The Romans are stated to have made the discovery of a species of wood which is immune, but their secret is lost, and so far as current knowledge goes, there is no timber which is indubitably free from liability to be attacked. As the result of the experiments carried out, the Committee came to the conclusion that "no process for the preservation

* Department of Scientiflc and Industrial Research. Deterioration of Structures of Timber, Metal and Concrete exposed to the Action of Sea-Water. Fifteenth Report of the Committee of the Institution of Civil Fingineers: being a General Description of the Experimental Work carried out by the Committee to date. Edited by S. M. Dixon Work carried out by the Committee to date. Edited by S. M. Dixon
and H. J. Grose. Pp. Xvi $+138+80$ plates. (London: H.M. Statjonery and H. J. Grose. Pp. Xvi 1 . 
of timber was more satisfactory than that of impregnation with creosote" and that "the efficacy of the process depended on the completeness with which the penetration of the creosote into the timber had been effected".

In order to increase the degree of penetration, incision of the fibres was resorted to, and the results of the operation are stated to have been satisfactory, the depth of the penetration being governed by the depths of the incisions, which had to be limited "in some cases" because there was a danger of injuring the timbers if the depth of the incisions exceeded $\frac{3}{4}$ inch. The warning is significant, and there are those who will feel that incision is a method to be used with extreme caution, since injury to the fibres can scarcely be avoided, with consequent impairment of strength. The normal process of impregnation with hot creosote does not appear to affect the strength of timber to any material degree, though high temperatures were observed to produce some reduction of strength. The arsenical compound, chlorodihydrophenarsazine, commonly called "D.M.", proved very deadly to Teredo when in the state of free swimming larvæ. The experiments did not definitely show creosote to be an efficient protection in the case of crustaceans, such as Limnoria, though it appeared to have some useful effect against Chelura. Prof. G. Barger contributes a detailed account of his experiments with various toxins, and Prof. S. M. Dixon describes his mechanical tests of foreign timbers, untreated and creosoted, with a note on incising.

The corrosion of metals constitutes a wide field of inquiry in itself, and though in the present instance limited to iron and steel, specimen bars of no less than fourteen different materials were selected for experiment: these included three representative rolled irons, four ordinary steels, two types of cast iron and five special steels. In their choice of specimens, the Committee had the advice of Sir Robert Hadfield, and the examination of the bars after exposure was made by Dr. J. Newton Friend. The test specimens

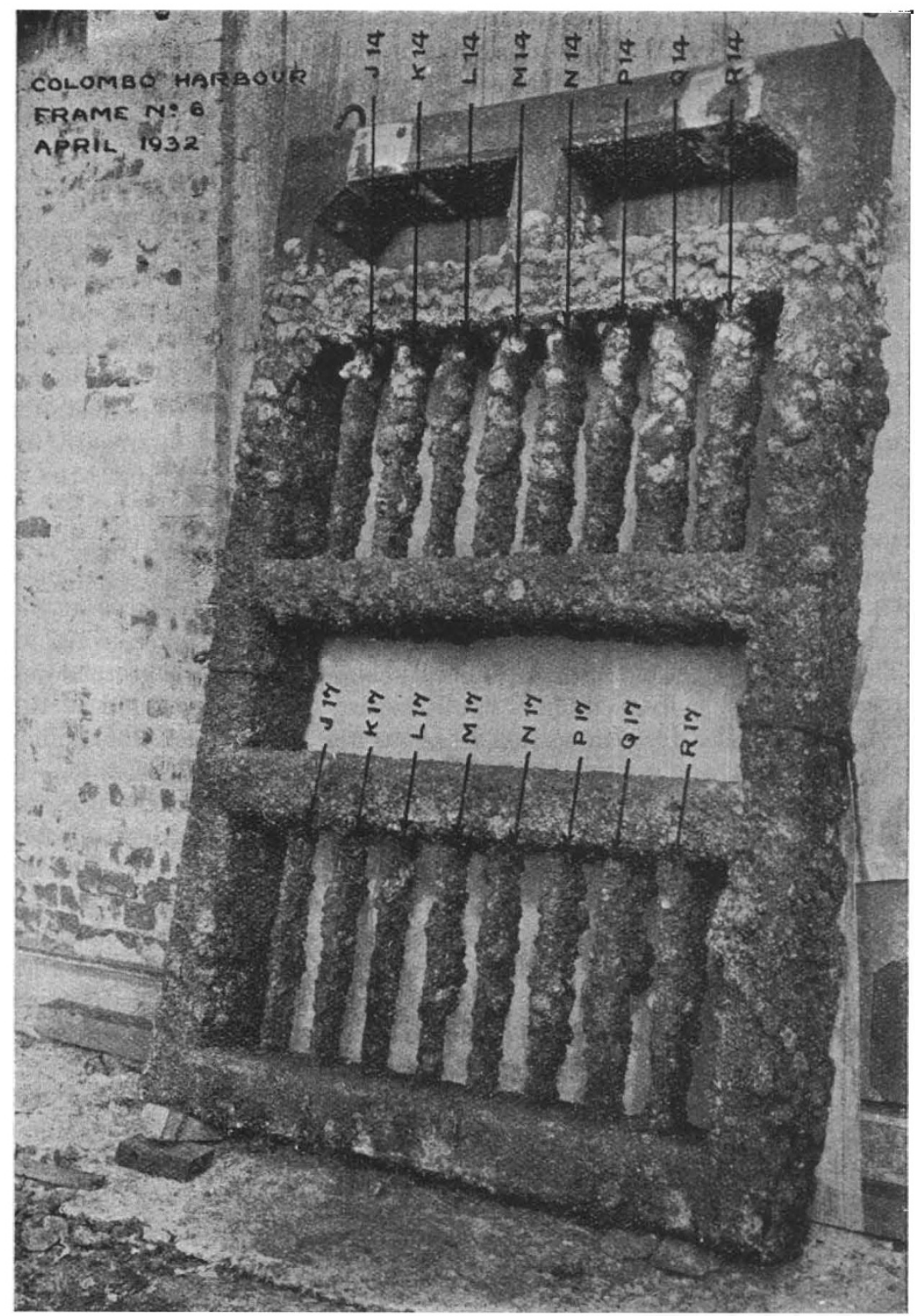

FIG. 2. Frame containing bars exposed to half-tide conditions (upper part) and to complete immersion in sea water (lower part) at Colombo for 10 years. Reproduced by permission of Crown copyright reserved.

were in general 24 in. long by 3 in. by $\frac{1}{2}$ in.

On the whole, there was found to be little to choose between the wrought irons and the ordinary carbon steels used in the research, as regards their mean resistance to the various types of corrosion studied; and increasing the carbon content of ordinary steel from about $0 \cdot 24$ to $0 \cdot 40$ per cent 
did not appear appreciably to affect the resistance of the metal against corrosion. The addition of 0.6 and $2 \cdot 2$ per cent of copper to mild carbon steel markedly increased the resistance of the metal to aerial and freshwater corrosion, but this advantage did not appear to be maintained in the half-tide and complete immersion tests in sea water. The addition of chromium proved beneficial in the tests above high-water mark, but in the halftide and complete immersion tests it resulted in excessive pitting. The best results were obtained by adding a proportion of nickel to the steel, an addition of 36.6 per cent rendering the material exceptionally resistant under all conditions. The cast irons resisted aerial corrosion exceedingly well and fresh-water reasonably well, but in the half-tide and complete immersion tests in sea water, corrosion frequently penetrated to the middle of the bars through pores and casting flaws. It is to be noted that the corrosion of the test bars was complicated by the occurrence of marine growths, including barnacles and oysters (Fig. 2).

The preservative effect of paints and other coatings on a number of mild steel plates $(2 \mathrm{ft}$. long by $6 \mathrm{in}$. wide by about $0 \cdot 1 \mathrm{in}$. thick) was studied, and the tests under the supervision of Dr. Newton Friend yielded results of much interest. The advantage of removing the mill-scale prior to coating, either by pickling or sand-blasting, was brought out clearly. Immersion in sea water and subsequent scraping was not so satisfactory. The plates were treated with red iron oxide paint (adopted as the standard for comparison) and with ordinary red lead paint with various $\mathrm{Pb}_{3} \mathrm{O}_{4}$ contents. The red lead paints showed distinet superiority in the aerial and half-tide experiments, but not in the total immersion tests. A series of plates were galvanized and a further set covered with tar and bituminous mixtures. Galvanizing proved very successful with a coating of about $20 \mathrm{oz}$. of zine per square yard. Coal tar gave excellent results and proved in all circumstances much better than iron oxide and lead paints. Bituminous solution gave poor results in aerial tests, but excellent results in the half-tide and complete immersion tests.

The experimental investigation of the durability of reinforced concrete in sea water has been conducted by Dr. R. E. Stradling. The experiments have involved the preparation of 474 reinforced concrete piles and 5,388 cylinders of different composition and treatment. The longest period of exposure experienced by any of these series as yet is only $5 \frac{1}{2}$ years, and it is therefore premature to draw other than merely tentative conclusions therefrom. As further examination may lead to modified views, it is scarcely advisable at this stage to do more than record the continuance of the exposure tests under various conditions at stations at Sheerness, Watford and the Gold Coast.

The volume, which is well illustrated and accompanied by diagrams and tables of great interest, will be of value to all who are in any way responsible for the maintenance of structures in a marine environment. It should be added that the research is now being carried on by means of the financial assistance received from a large number of dock and harbour authorities. There is a good index.

In connexion with the foregoing review, it is appropriate to notice a paper on "The Corrosion of Iron and Steel" by Sir Robert Hadfield and Mr. S. A. Main which was read at a meeting of the Institution of Civil Engineers on April 7. The paper was essentially an extension and amplification of the Committee's Report, in that it surveyed more completely the field of investigational activities in regard to the corrosion of ferrous metals since 1922 , the date of a previous paper on the subject by Sir Robert Hadfield. Emphasis was laid on the importance of the study of corrosion from the testimony of Dr. F. N. Speller, director of research at the National Tube Company, Pittsburgh, U.S.A., who had made a careful estimate of the total amount of steel in use in the world and found it to be about 1,200 million tons, of which 700 million tons is probably in use in the United States. Dr. Speller further estimated that about 75 per cent of the steel requires protection in order to be used.

Alluding to the work of the Committee, it was stated that altogether 1,350 specimens of carbon and special steels were prepared by Messrs. Hadfields of Sheffield for experimental purposes, and that in regard to exposure to air, the order of increasing severity for general wastage at the stations selected for observation was invariably Halifax (Nova Scotia), Auckland, Plymouth and Colombo. Climatic temperature, which is highest at Colombo and lowest at Halifax, evidently must have a definite influence in promoting aerial corrosion. This factor, however, did not operate to the same extent under half-tide conditions or for total immersion: presumably, therefore, the local character of the sea water may be of more importance than its temperature. The evidence of the behaviour of iron and steel under half-tide conditions is especially instructive, being contrary to the widely accepted idea that exposure "between wind and water" is particularly favourable to corrosion. In the great majority of cases among ordinary steels and rolled irons, the wastage at half-tide is intermediate between that experienced under aerial and total immersion conditions.

The authors gave some examples of the severity 
of the corrosion experienced in the Gulf of Paria, where the United British Oilfields of Trinidad, Ltd., reported that a 5/16 in. mild steel plate, forming the bottom of a storage tank, was eaten through in nine months. Among the protective measures discussed, special mention was made of oxide films, not more than 1.6 millionths of an inch in thickness, yet capable of providing an armour, or first line of defence against corrosion.
In most cases of general wastage of steel, the removal of the rolling-mill scale, prior to exposure, had the effect of increasing the amount of corrosion, but, on the other hand, as regards pitting, its influence was almost entirely favourable. The wastage of cast iron was generally very much less than that of the rolled irons and steels, and the pitting in a five-year test was negligible.

Brysson CUNNINGHam.

\title{
Insect Life of Temporary Rain Swamps in British Guiana
}

\author{
By F. A. Squire, Department of Agriculture, British Guiana
}

$\mathrm{T}$ WICE a year, during the months immediately preceding and following the solstices, the lowlying, badly drained grasslands of the coastal belt of British Guiana are converted into temporary swamps by the heavy rains which fall during those periods. This condition naturally varies a good deal in extent and duration, but generally lasts for at least several weeks. In that time the swamps become the home of innumerable insects of diverse species, some of them of the greatest concern to mankind, and all of them very interesting.

The following account is based on observations made during the mid-year rainy season of 1935 . The rains commenced on May 16 and continued with daily precipitations and frequent heavy downpours up to the end of June, when dry spells began to intervene. Up to this point the season was typical, but an opportunity to prolong the investigation was afforded by an unusually wet July and August. The rainfall recorded at the Botanic Gardens, Georgetown, for the months in question was: May, 11.56 in., June, 14.37 in., July, 8.12 in. and August, 13.78 in., totalling 47.83 in. With the cessation of the rains, the swamps drain off and vanish almost as suddenly as they appear, so that there is never any stagnation.

Bearing in mind the abruptness of the onset of the rains, it is perhaps scarcely necessary to labour the point that when these aquatic conditions arise, there is a complete and somewhat sudden change in the savannah population-the dry season dwellers evacuating their territory with a good deal of haste and panic, and often with considerable loss of life. This is quite commonly observed in the case of Solenopsis, the red stinging ant. This notorious insect infests, and often monopolizes, the countryside - especially low-lying grasslands. Here it establishes its colonies in ever-increasing numbers, and it would, in a short time, surely become a terrible scourge but for the blessed ruthlessness of Nature. With the advent of the rains and the flooding of the savannahs, these colonies are promptly inundated. How the ant meets this parlous situation by forming living rafts for the purpose of salvaging the brood and fertile queens is well known. But how many of these castaways ever reach safety, and what is the extent of the subterranean mortality?

Even more disastrous is the effect of the floods on other underground insects, especially the larvæ and pupæ of humous and root-feeding Coleoptera. These frequently have no aquatic adaptations, and are consequently easily overcome by excessive moisture. These inhabitants of the soil have, presumably through natural selection, come to pass their more defenceless stages during the dry seasons. But this arrangement is precarious, for the weather is often capricious, and unseasonable deluges not infrequently occur, creating very unfavourable conditions for the soil fauna. The Dynastids, Dyscinetus geminatus and $D$. bidentatus, in particular, are very adversely affected, and may be prevented from making their appearance in pestilential numbers for several years by such an occurrence. Tangible evidence of the havoc caused is not lacking, for the receding waters leave behind them innumerable dead grubs scattered over the countryside.

Above the ground another story is told. The rather populous Orthoptera and Hemiptera that may, in dry weather, be swept up from any patch of grass, are better equipped for flight to higher levels ; yet many are trapped, and may be seen clinging to a hopeful blade of grass or making sorry efforts to swim with ill-adapted limbs. There is, indeed, one local grasshopper which, I believe, must be unique, whose life is normally passed in semi-aquatic surroundings and whose hind-tibiæ are curiously suited to this element, being flattened and expanded to form paddles. 